\title{
Deposition parameters and annealing key role in setting structural and polar properties of $\mathrm{Bi}_{0.9} \mathrm{La}_{0.1} \mathrm{Fe}_{0.9} \mathrm{Mn}_{0.1} \mathrm{O}_{3}$ thin films
}

\author{
T. T. Carvalho ${ }^{1,4} \cdot$ F. G. Figueiras ${ }^{1,2} \cdot$ S. M. S. Pereira ${ }^{2}$ J. R. A. Fernandes ${ }^{3} \cdot$ \\ J. Perez de la $\mathrm{Cruz}^{1} \cdot$ P. B. Tavares ${ }^{4} \cdot$ A. Almeida $^{1} \cdot$ J. Agostinho Moreira $^{1}$
}

Received: 11 January 2017 / Accepted: 5 May 2017 / Published online: 16 May 2017

(C) Springer Science+Business Media New York 2017

\begin{abstract}
The present work explores the processing conditions of $\mathrm{Bi}_{0.9} \mathrm{La}_{0.1} \mathrm{Fe}_{0.9} \mathrm{Mn}_{0.1} \mathrm{O}_{3}$ (BLFM) thin films, grown by RF sputtering on platinum metalized silicon substrates, and its impact on the structural and ferroelectric properties. The optimized processing conditions were found to be a combination of deposition of an amorphous film at low substrate temperature $\left(\leq 550^{\circ} \mathrm{C}\right)$, followed by a thermal treatment at $550^{\circ} \mathrm{C}$ during $30 \mathrm{~min}$, in order to prevent bismuth volatilization. This procedure leads to the formation of high-quality monophasic crystalline films with well-defined piezoelectric response exhibiting micron size domains.
\end{abstract}

\section{Introduction}

The potential use of the multiferroic $\mathrm{BiFeO}_{3}$ (BFO) in thin film form represents an advanced step for the development of a new generation of micro and nanoelectronic devices [1]. Regarding the crystalline structure, ab initio calculations have shown that there are a number of distinct

T. T. Carvalho

ttranchete@fc.up.pt

1 IFIMUP-IN, Physics and Astronomy Department, Faculty of Sciences, University of Porto, R. Campo Alegre, 687, 4169-007 Porto, Portugal

2 CICECO-AIM and Physics Department, University of Aveiro, 3810-193 Aveiro, Portugal

3 INESC TEC and Physics Department, University of Trás-os-Montes e Alto Douro, 5001-801 Vila Real, Portugal

4 CQVR and Chemistry Department, University of Trás-os-Montes and Alto Douro, 5001-801 Vila Real, Portugal monoclinic phases (i.e. $P c, C m, C c$ ), which compete with each other and thus the actual stabilized phase critically depends on the substrate mediated strain, growth conditions and temperature [2]. Consequently, single-phase BFO thin films have a narrow processing window, making the control of the whole set of deposition parameters a very challenging task $[3,4]$. It is well known that the substrate temperature and partial oxygen pressure play a major role in the growth of single-phase films. For instance, at low substrate temperature $\left(\sim 550^{\circ} \mathrm{C}\right)$ or high partial oxygen pressure $\left(10^{-1}\right.$ mbar) $\mathrm{Bi}_{2} \mathrm{O}_{3}$ is formed, while at high temperatures $\left(>650^{\circ} \mathrm{C}\right)$ or low partial oxygen pressure $\left(10^{-3}\right.$ mbar), the $\mathrm{Fe}_{2} \mathrm{O}_{3}$ phase has been found [3, 4]. The effect of annealing treatments on the properties of BFO thin films has also been studied and it was clearly shown the significant effect of the annealing temperature on microstructure, surface morphology and ferroelectric properties [5]. Somrani et al. showed that both partial oxygen pressure and annealing treatment play a key role on the formation of the crystalline phase. These authors obtained high (100)-oriented BFO films on Si substrate at $700{ }^{\circ} \mathrm{C}$ and atmospheric pressure for a deposition time of $1 \mathrm{~h}$ [6].

Substrate induced strain also plays a critical role on the structural and physical properties of thin films. The strain induced phase transition in BFO has been recently reviewed [7]. The symmetry of strained BFO films has been found to be neither purely rhombohedral nor tetragonal, but a monoclinic crystal structure that changes from nearly rhombohedral ("R-like") to nearly tetragonal ("T-like") at strains exceeding $-4.5 \%$, with the "T-like" structure being characterized by a highly-enhanced c/a ratio. In the review work it is also considered the role of stoichiometry and growth conditions on the stabilization of the "T-like" phase [7]. Among all the phases reported, films with large c/a ratio present enhanced electromechanical response at 
morphotropic phase boundary (MPB) [8]. Furthermore, it has been shown that compressive stress reduces the symmetry by producing a remarkable elongation of the out-ofplane cell parameter, and thus an increase of $c / a$ ratio, giving rise to a "T-like" phase with high electric polarization (75 and $\left.150 \mu \mathrm{C} / \mathrm{cm}^{2}\right)$ [9, 10].

Despite the interesting ferroelectric and magnetic properties exhibited by bulk BFO at room temperature, some drawbacks still limit its applications, mainly due to high leakage current, associated with secondary phases [11]. Different attempts have been made in order to overcome these handicaps such as through partial substitution of $\mathrm{Bi}$ ion by rare earth ions (such as $\mathrm{La}, \mathrm{Pr}, \mathrm{Nd}$ ) or/ and of iron by transition metal ions (like Ti, $\mathrm{Cr}, \mathrm{Mn}$ ) [12, 13]. Previous studies have shown that the partial substitution of bismuth by lanthanum inhibits the formation of secondary phases [14], while the introduction of manganese in the Fe-site has been used in order to suppress the valence fluctuation of the $\mathrm{Fe}^{3+}$ ions, allowing for ferromagnetic ordering [13]. Simultaneous substitution of lanthanum and manganese yields low leakage current density and improves ferromagnetic behavior $[15,16]$. Despite the relevance in studying $\mathrm{Bi}_{1-\mathrm{x}} \mathrm{La}_{\mathrm{x}} \mathrm{Fe}_{1-\mathrm{y}} \mathrm{Mn}_{\mathrm{y}} \mathrm{O}_{3}$ (BLFM) system, up to now just a few works in bulk and thin film form were published. Lahmar et al. studied structural transitions in $90 \% \mathrm{BiFeO}_{3}-10 \% \mathrm{RMnO}_{3}(\mathrm{R}=\mathrm{Ho}, \mathrm{Gd}$, and $\mathrm{La})$ thin films, wherein it was ascertained a structural transition from monoclinic to orthorhombic symmetry $[15,17$, 18]. Several researchers have investigated the effect on their physical properties by using different substrates, substrate orientations, and buffer layers [19-21]. Recently, thermal treatment studies performed by Feigl et al. on rhombohedral doped La:BFO thin films, have evidenced the control of ferroelastic domain pattern by post deposition conditions [22]. Appropriate heat treatment can change the domain pattern, yielding the possibility to create films with stripe domain patterns [22]. A recent study has shown that a $0.3 \mathrm{mbar}$ partial oxygen pressure is essential to enable the growth of (100)-oriented films [23]. Moreover, Kolte et al. have studied the effect of substrate temperature on the structural and electrical properties of $\mathrm{Bi}_{0.90} \mathrm{La}_{0.10} \mathrm{Fe}_{0.95} \mathrm{Mn}_{0.05} \mathrm{O}_{3}$ (BLFM) thin films deposited on $\mathrm{Pt}(111) / \mathrm{Ti} / \mathrm{SiO}_{2} / \mathrm{Si}$ substrate using pulsed laser deposition [24]. The experimental results reveal that the temperature window to obtain single phase and ferroelectric films is very narrow, like the case of BFO films. According to these authors, as the substrate temperature increases up to $575^{\circ} \mathrm{C}$, both remnant polarization and coercive field increase and thereafter decrease. In fact, it was ascertained that films deposited at $575^{\circ} \mathrm{C}$ exhibit maximum remnant polarization close to $39 \mu \mathrm{C} / \mathrm{cm}^{2}$ [24]. The observed electric permittivity decrease with increasing substrate temperature can be either due to the presence of secondary/impurity phase or to the formation of dead layer at the BLFMO/Pt interface [24]. Thus, an alternative processing route is mandatory towards ensuring a high crystalline and chemical quality of BLFM films.

This work aims at studying the effect of annealing treatment on the structural and electric properties of $\mathrm{Bi}_{0.9} \mathrm{La}_{0.1} \mathrm{Fe}_{0.9} \mathrm{Mn}_{0.1} \mathrm{O}_{3}$ thin films. In the first part, we will determine the optimal deposition temperature range to grow the thin films. In the second part, we will carry out post annealing treatment of the as-deposited amorphous films and analyze the structure, stoichiometry and ferroelectric properties by using X-ray diffraction (XRD), energydispersive $\mathrm{X}$-ray spectroscopy (EDS) and piezoresponse force microscopy (PFM).

\section{Experimental methods}

Thin films were deposited by RF sputtering on metalized platinum substrates $\left[\mathrm{Pt} / \mathrm{Ti} / \mathrm{SiO}_{2} / \mathrm{Si}(100)\right]$, using an $U S$ GUN II 2" sputter source with an applied RF power of $100 \mathrm{~W}$. For this purpose, a $\mathrm{Bi}_{0.9} \mathrm{La}_{0.1} \mathrm{Fe}_{0.9} \mathrm{Mn}_{0.1} \mathrm{O}_{3}$ ceramic target, with $5 \mathrm{~cm}$ in diameter, was synthesized by sol gel combustion method, and fully characterized, as previously reported [25]. The films were deposited during $30 \mathrm{~min}$ at fixed substrate temperatures, between 400 and $650^{\circ} \mathrm{C}$, using a 9:1 argon/oxygen ratio at $1.2 \times 10^{2}$ mbar pressure in the deposition chamber. Films deposited at low temperature, which are amorphous, were further annealed in air at $550^{\circ} \mathrm{C}(30 \mathrm{~min})$, and $575^{\circ} \mathrm{C}(2,4$, and $22 \mathrm{~h})$, with fast cooling rate (denominated by annealed films). Systematic characterization of the as-processed films was performed in order to determine the effect of the deposition conditions on their structure, morphology and chemical composition. $\mathrm{X}$-ray diffraction data were collected at room temperature in a PANalytical X'Pert Pro diffractometer, equipped with $X$ 'Celerator detector and secondary monochromator. The measurements were carried out in $\boldsymbol{\theta} / 2 \boldsymbol{\theta}$ Bragg-Brentano geometry, using $\mathrm{CuK} \alpha$ radiation $(\lambda=0.15418 \mathrm{~nm})$, from $20^{\circ}$ to $60^{\circ}$, at $0.017^{\circ}$ step width and $150 \mathrm{~s} /$ step of counting time. For the crystalline orientation study or in the pole-figure measurement, the diffracted beam intensity is measured in a $c$ range from $0^{\circ}$ to $80^{\circ}$, while keeping fixed the position of the detector at a specific reflection angle $2 \boldsymbol{\theta}$. Pole densities are plotted in stereographic projection with polar angle c. The plane of the stereographic projection is chosen parallel to the sample surface. Unpolarized micro-Raman spectra were recorded at room temperature by using a $T 64000$ spectrometer, and $514.5 \mathrm{~nm}$ as excitation, in the spectral range $200-850 \mathrm{~cm}^{-1}$. The laser power at the sample was $5 \mathrm{~mW}$, in order to avoid sample self-heating. The morphology and stoichiometry of the films were analyzed by SEM/ EDS with a FEI Quanta 400/EDAX. Local piezoelectric response of the films surface was investigated by PFM 
using a NT-MDT Ntegra equipped with a lock-in amplifier (SR-830A Stanford Research), a function generator (FG120, Yokagawa) and appropriate Nanosensors PPP-NCHR cantilevers. Bias lithography encompasses regions that were stimulated at $\pm 20 \mathrm{~V}_{\text {d.c. }}$. and $1 \mathrm{~Hz}$ line scan rate.

\section{Results and discussion}

\subsection{Substrate temperature}

The first step of this work is to study the effect of the substrate temperature on the stoichiometry and crystal structure of the in situ grown $\mathrm{Bi}_{0.9} \mathrm{La}_{0.1} \mathrm{Fe}_{0.9} \mathrm{Mn}_{0.1} \mathrm{O}_{3}$ (BLFM) thin films. Figure 1 shows XRD patterns of the BLFM target and of the series of films deposited at fixed substrate temperatures, between 400 and $650{ }^{\circ} \mathrm{C}$. Following the substrate induced epitaxy, the Bragg peaks observed in the XRD pattern of the films were indexed according to a pseudo-cubic unit cell [4]. The diffractograms of the films deposited at substrate temperatures below $550^{\circ} \mathrm{C}$ exhibit only the Bragg peaks arising from the substrate, evidencing that these films are mainly amorphous. For the films deposited at higher substrate temperature, additional well-defined Bragg peaks are observed, pointing out to the formation of a crystalline phase. In particular, the films deposited at 550 and $575^{\circ} \mathrm{C}$ present very well defined (100) $\mathrm{c}$ and (110)c peaks from the $\mathrm{BiFeO}_{3}$ phase. However, as the substrate temperature increases from 625 to $650^{\circ} \mathrm{C}$, the intensity of these Bragg peaks decreases. These results can be explained by the formation of $\gamma-\mathrm{Fe}_{2} \mathrm{O}_{3}$ phase, due

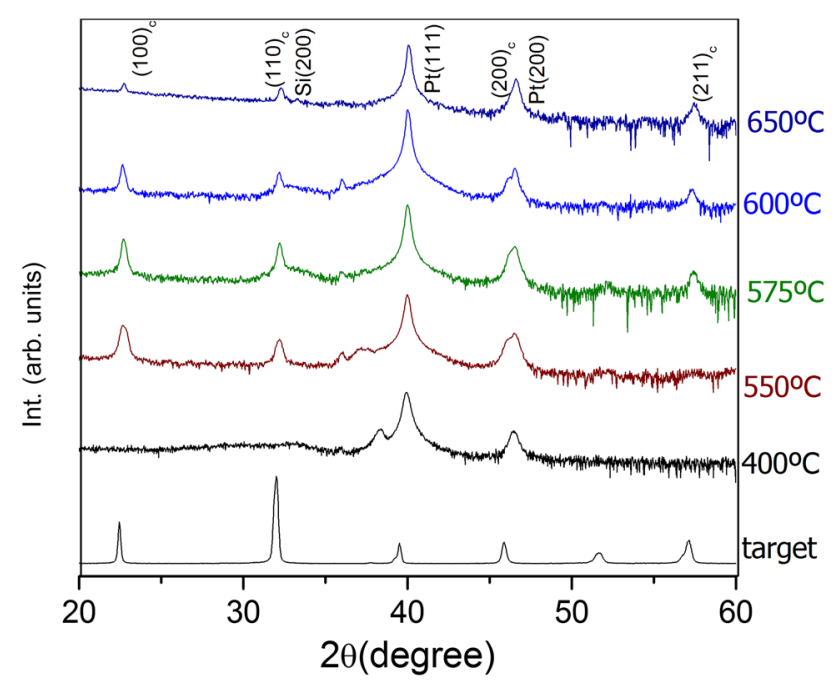

Fig. 1 Room temperature XRD patterns of the target and as-grown thin films deposited by RF sputtering at different substrate temperatures. Bragg peaks signalized with a (c) are assigned to the pseudocubic BLFM phase to bismuth volatilization, as it is evidenced in Table 1 , and already pointed out by Béa et al. in BFO films, deposited at high temperatures [8].

Figure 2a, b show, respectively, a cross-section SEM image and AFM topographic scan of the film deposited at $550^{\circ} \mathrm{C}$, where are considered representative for the whole film series. Microscopy examination reveals a film with different layers corresponding to the substrate and film. It is observed a uniform profile and good adhesion to the Pt buffer, a typical thickness between 120 and $150 \mathrm{~nm}$, a homogeneous and smooth surface, an average roughness below $8 \mathrm{~nm}$, and a crystallite size $<200 \mathrm{~nm}$. EDS measurements reveal a significant loss of Bi content with increasing substrate temperature, as it is listed in Table 1. Moreover, the $\mathrm{Bi} / \mathrm{Fe}$ ratio is 1.02 for the films deposited at $500^{\circ} \mathrm{C}$, and decreases as the substrate temperature increases, reaching the value of 0.5 for the film deposited at $650^{\circ} \mathrm{C}$.

Figure 3 shows the unpolarized Raman spectra of the target and the crystalline films deposited at several fixed substrate temperatures, from 550 to $650^{\circ} \mathrm{C}$. The Raman spectrum of the target exhibits several bands below $400 \mathrm{~cm}^{-1}$, which are assigned to lattice vibrations involving the $\mathrm{Bi}^{3+}$ and $\mathrm{La}^{3+}$ ions [26]. As it can be observed from Fig. 3, these bands are rather intense in the Raman spectra of films deposited at substrate temperatures below to $600^{\circ} \mathrm{C}$, and very weak in the Raman spectrum of the film deposited at $650^{\circ} \mathrm{C}$. The decrease of intensity of vibrational bands associated with A-site cation motion points to a volatilization of $\mathrm{Bi}^{3+}$, which, in turn, suggests the presence of spurious iron oxide phases in this film, most likely hematite. In fact, the Raman bands located at 222, 289 and $406 \mathrm{~cm}^{-1}$ (signalized by * in Fig. 3) are assigned to $\mathrm{A}_{1 \mathrm{~g}}$ and $\mathrm{E}$ modes of $\mathrm{Fe}_{2} \mathrm{O}_{3}$ hematite [27, 28]. The volatilization of $\mathrm{Bi}^{3+}$ is corroborated by the EDS analysis of the films (see Table 1). The volatilization of $\mathrm{Bi}^{3+}$ creates defects and disorder in the crystal lattice, which also explains the decrease of the intensity of both the Bragg peaks of the XRD pattern and the lattice Raman bands below $400 \mathrm{~cm}^{-1}$. The strong and broad Raman band located close to $630 \mathrm{~cm}^{-1}$ is assigned to the symmetric stretching mode of the $\mathrm{MnO}_{6}$ octahedra $[29,30]$. The existence of this band, observed in the Raman spectra of the target and the films deposited at temperatures above to $550{ }^{\circ} \mathrm{C}$, evidences the incorporation of $\mathrm{Mn}^{3+}$ ion at the B lattice site.

Table $1 \mathrm{Bi} / \mathrm{Fe}$ ratio obtained from EDS results for the series of samples

\begin{tabular}{ll}
\hline $\begin{array}{l}\text { Film deposited @ } \\
\text { temperature }\left({ }^{\circ} \mathrm{C}\right)\end{array}$ & Bi/Fe ratio \\
\hline 500 & 1.02 \\
550 & 0.89 \\
600 & 0.79 \\
650 & 0.50 \\
\hline
\end{tabular}


Fig. 2 a SEM image of a cross section, and $\mathbf{b}$ AFM surface topography of the thin film grown at $550^{\circ} \mathrm{C}$

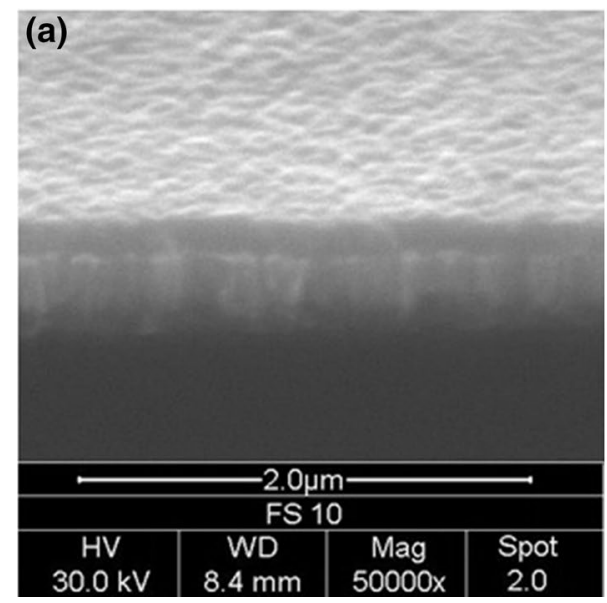

(b)

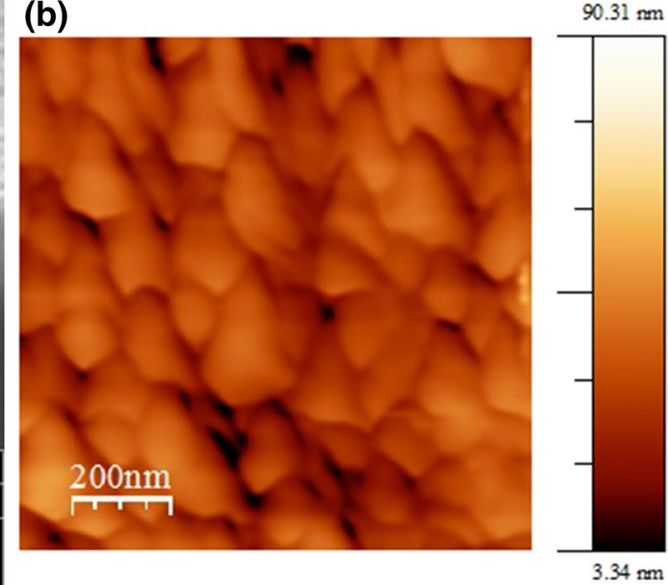

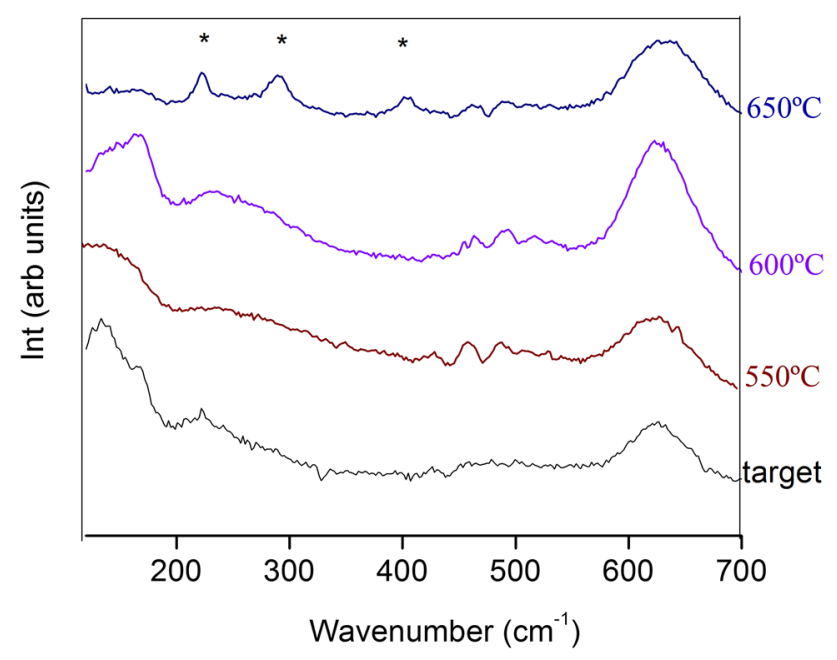

Fig. 3 Room temperature Raman spectra of thin films grown at different temperatures. Raman bands of $\mathrm{Fe}_{2} \mathrm{O}_{3}$ are indicated with asterisk symbol

The resistive behavior of the as-grow films was studied by leakage current measurements. The current density measured at room temperature for the film grown at $575^{\circ} \mathrm{C}$ is $3.7 \times 10^{-4} \mathrm{~A} / \mathrm{cm}^{2}$ at $50 \mathrm{kV} / \mathrm{cm}$. Films deposited at higher temperatures show higher leakage current densities, which could not be ascertained as the values were out of range of the measuring technique. The increase of the current density with increasing substrate temperature is directly associated with the existence of bismuth and oxygen vacancies in the films, as it was previously observed for BFO thin films and already evidenced in this work [4].

Summarizing the main results presented in this section, the experimental data emphasize that the in situ growth window temperature for BLFM film processing is very narrow $\left(550-600{ }^{\circ} \mathrm{C}\right)$, similar to the temperature for which the best $\mathrm{BFO}$ films were obtained [3, 4].

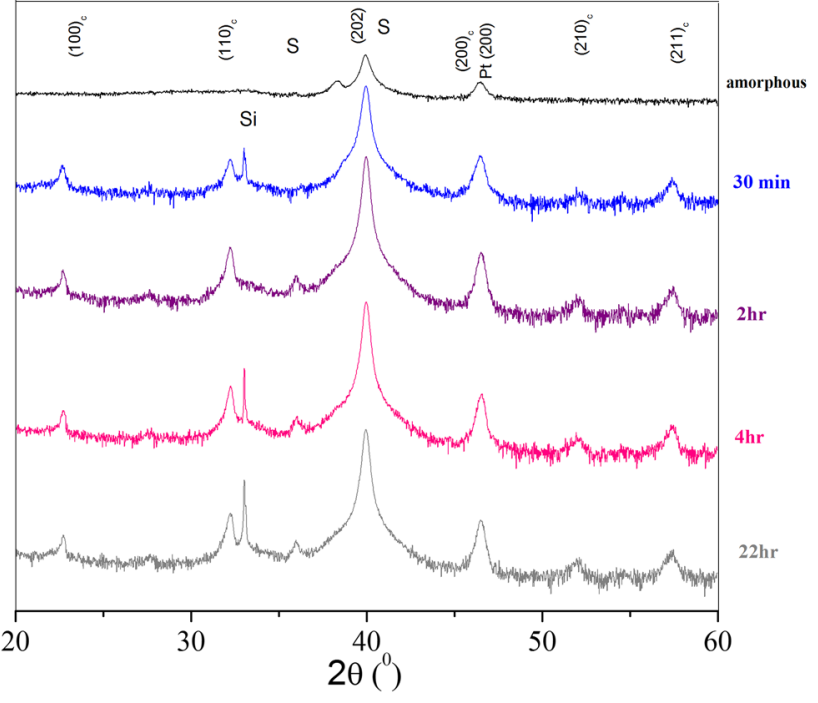

Fig. 4 Room temperature X-ray diffraction patterns of thin films annealed at $550^{\circ} \mathrm{C}(30 \mathrm{~min})$, and $575^{\circ} \mathrm{C}(2,4$, and $22 \mathrm{~h})$. Peaks signalized with an (S) and a (C) are assigned to substrate and pseudocubic BLFM phase, respectively

\subsection{Annealing treatment}

In this section, we will present the results obtained from the study of the post annealing process on the structure and stoichiometry of the BLFM thin films. We have proceeded as follows: Firstly, amorphous BLFM films onto Pt/ $\mathrm{Ti} / \mathrm{SiO}_{2} / \mathrm{Si}(100)$ were deposited, at temperature substrate below $500^{\circ} \mathrm{C}$, using a 9:1 $\mathrm{Ar} / \mathrm{O}_{2}$ atmosphere, at $1.2 \times 10^{-2}$ mbar. Secondly, a post annealing of the as-processed films was carried out, at 550 and $575^{\circ} \mathrm{C}$, for different annealing time intervals, between 30 min up to $22 \mathrm{~h}$, and at atmospheric pressure.

Figure 4 shows representative room temperature XRD patterns of a non-annealed amorphous film, and of those ones, which were annealed at $550^{\circ} \mathrm{C}(30 \mathrm{~min})$, and $575^{\circ} \mathrm{C}$ 
(2, 4, and $22 \mathrm{~h})$. The latter patterns exhibit well-defined Bragg peaks, arising from the BLFM phase. Peak position is almost independent of the annealing time and temperature. The peak emerging at about $2 \theta=36^{\circ}$ is assigned to a substrate Bragg peak. No traces of spurious phase could be detected in the limit of the experimental technique. The peak located at $2 \theta=33.0^{\circ}$ is assigned to the forbidden (200) peak of Si. The emergence of the (200) peak differs significantly from measurement to measurement. This feature is usually known as "Umweganregung", being the intensity and peak shape dependent on three parameters: the in-plane orientation of the sample $\phi$, the divergence of the used diffractometer perpendicular to the diffraction plane, and the wavelength distribution in the incident beam [31].

In order to study the effect of the post annealing treatment on the stoichiometry of the films, EDS analysis was also carried out. In this work, we have focused on the $\mathrm{Bi}$ / Fe ratio in the $30 \mathrm{~min}$ and $22 \mathrm{~h}$ annealed films. The former film exhibits a $\mathrm{Bi} / \mathrm{Fe}$ ratio of 0.97 , while for the latter film a $\mathrm{Bi} / \mathrm{Fe}$ ratio of 0.90 was obtained. These results clearly show that the post annealing process at $550{ }^{\circ} \mathrm{C}$ during $30 \mathrm{~min}$ is able to promote the BLFM phase with the higher $\mathrm{Bi} / \mathrm{Fe}$ ratio, foreseen for stoichiometric BLFM.

In the next, we will focus our attention on the films post annealed at $550^{\circ} \mathrm{C}$ during $30 \mathrm{~min}$. In order to study the lattice distortions in this film, we have traced detailed pole figures, centered at two different Bragg peaks $\left(2 \boldsymbol{\theta}=22.5^{\circ}\right.$ and $32.1^{\circ}$ ), which are shown in Fig. 5a, b, respectively. For the pole figure centered on the reflection at $2 \boldsymbol{\theta}=22.5^{\circ}$ (Fig. 5a), four elongated lobes stemming from the center are observed. These lobes start to be aligned with the substrate edges, and then rotate about $\phi$ up to $35^{\circ}$ away from the original axes directions. This behavior can be interpreted as a manifestation of the cumulative effect of a small adjustment in the crystallographic $\beta$ angle away from $90^{\circ}$, evidencing a monoclinic distortion, as the film relax away from the initial cubic symmetry induced by the substrate. This result is also corroborated by the pole figure centered at $2 \boldsymbol{\theta}=32.1^{\circ}$ (Fig. 5b), in which four reflections, assigned to the family of planes (101) and (011) at $\boldsymbol{\psi} \sim 34^{\circ}$, are clearly displaced by $30^{\circ}$ in relation to the substrate axis. Moreover, the lobes observed in Fig. 5a at $\phi \sim 70^{\circ}, 160^{\circ}$, $250^{\circ}$, and $340^{\circ}$ also suggest the possibility of an additional tetragonal distortion, as it has been referred to in the earlier literature.

The aforementioned observed distortions point out for a symmetry lowering of the BLFM phase, which can be compatible with the presence of a non-centrosymmetric structure. Henceforth, it becomes paramount to ascertain the possible existence of ferroelectric domains in this film.

Since dielectric/ferroelectric measurements using conventional electrodes in a capacitor geometry are not viable due to extensive current loss, further inspection of possible ferroelectric properties was performed at submicron scale via scanning force microscopy studies based on piezo-response mode (PFM) [32]. The series of images in Fig. 6a, b correspond, respectively, to PFM scans on the post annealed films at $575^{\circ} \mathrm{C}$ during $22 \mathrm{~h}$, and on the post annealed films at $575^{\circ} \mathrm{C}$ during $30 \mathrm{~min}$. Theses series of images enable to compare the effect on domain arrangement for different $\mathrm{Bi} / \mathrm{Fe}$ ratios. Both films exhibit homogeneous surface morphology with roughness below $4 \mathrm{~nm}$, and some crystallites reaching up to $600 \mathrm{~nm}$ in size. Piezoresponse amplitude and phase contrast scans are clearly correlated, while independent of cross-talk to surface morphology, hence discarding charge accumulation effects, and thus enabling to discriminate proper domains signatures. The longer time annealed film reveals a relatively faint piezo-response amplitude and phase contrast with domains arrangement reaching $2 \mu \mathrm{m}$ in size. Biased poling lithography experiments in this film could not promote any polar imprint even up to $\pm 20 \mathrm{~V}_{\mathrm{dc}}$. Higher voltages yield local electric discharge and surface disruption. The film with shorter annealing treatment reveals piezo-response amplitude and phase scans with clear contrast and well-defined domains extending for more than $1 \mu \mathrm{m}$ long, which encircle several crystallites. A deeper insight of the polar properties of this film is illustrated in the sequences of images in Fig. 6b, c, which include the piezo-contrast amplitude and piezo-contrast phase, after lithographic bias poling at $+12.5 \mathrm{~V}_{\mathrm{dc}}$ (contour) and at $-12.5 \mathrm{~V}_{\mathrm{dc}}$ (enclosed) concentric square regions. These images clearly show an intensification of the signal with highly contrasting imprints in the respective stimulated regions. Moreover, it can be observed an appropriate domain reversal in the central region under lithographic overwriting. The conjugation of these results points out to a coherent ferroelectric response of the studied film at the submicron level [33].

\section{Conclusions}

This work reports the effect of RF sputtering deposition parameters and annealing temperatures on the structure, stoichiometry, and polar properties of $\mathrm{Bi}_{0.9} \mathrm{La}_{0.1} \mathrm{Fe}_{0.9} \mathrm{Mn}_{0.1} \mathrm{O}_{3}$ thin films. In-situ BLFM phase formation occurs in a very narrow window $\left(550-600^{\circ} \mathrm{C}\right)$, similar to the temperature range required for BFO films, although a deviation from the stoichiometry is observed. Moreover, for temperature higher than $600^{\circ} \mathrm{C}$ a significant bismuth volatilization occurs. In order to preserve the stoichiometry of the films, we carried out annealing treatment on the amorphous films. The annealing treatment was performed at 550 and $575^{\circ} \mathrm{C}$, for different annealing time intervals, between $30 \mathrm{~min}$ and $22 \mathrm{~h}$, and at atmospheric pressure. XRD patterns reveal that peak position is almost independent of the annealing 

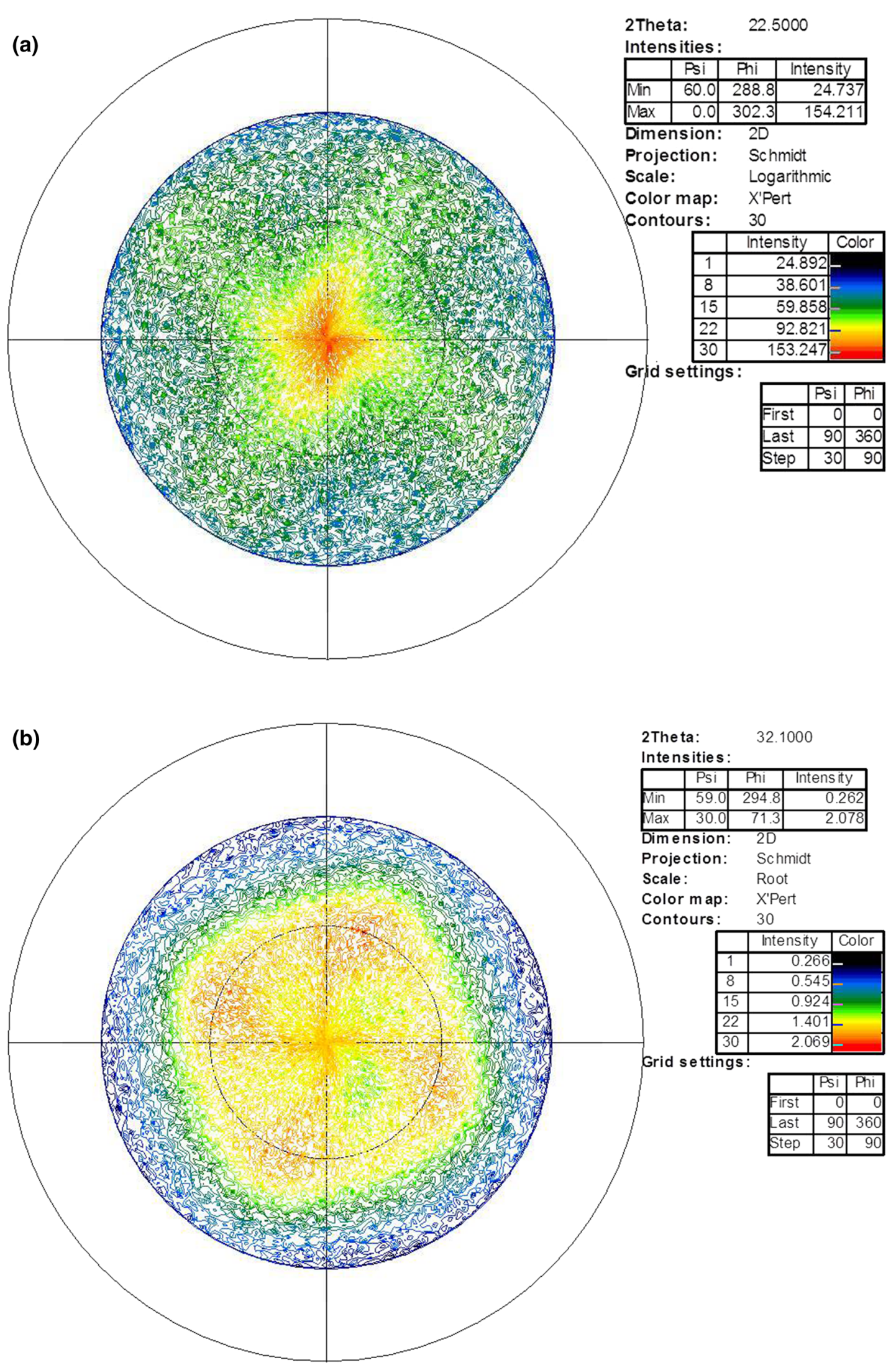

Fig. 5 Pole figures of the thin film annealed at $550{ }^{\circ} \mathrm{C}$ for $30 \mathrm{~min}$ a at $2 \boldsymbol{\theta}=22.5^{\circ}$ and $\mathbf{b}$ at $2 \boldsymbol{\theta}=32.1^{\circ}$ 
(a)

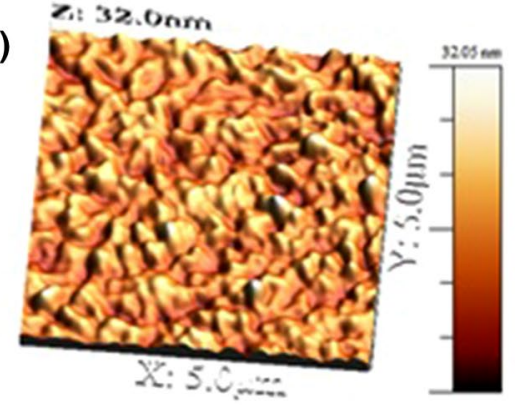

2: $35.3 \mathrm{~nm}$

(b)

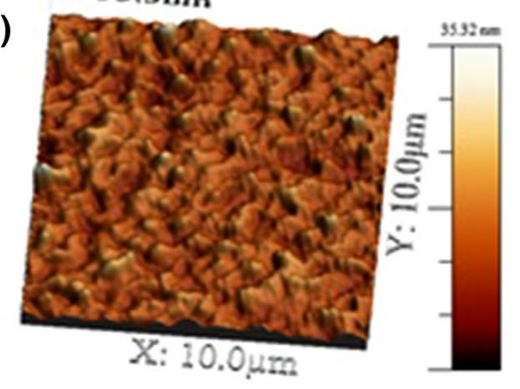

(c)

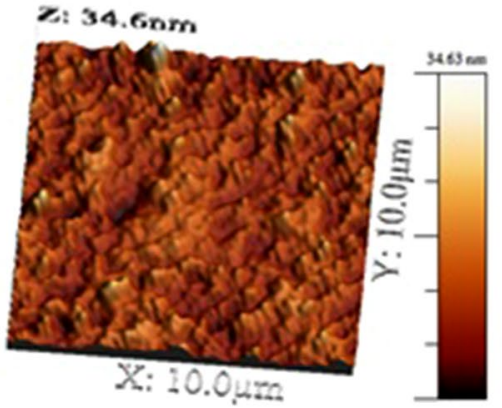

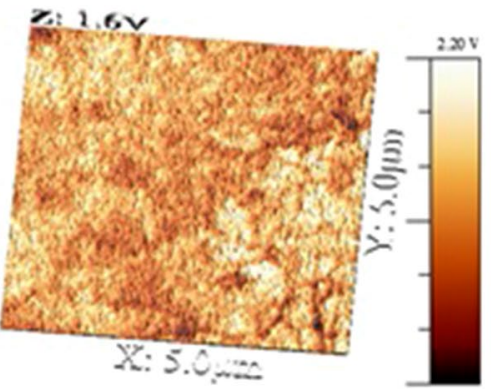
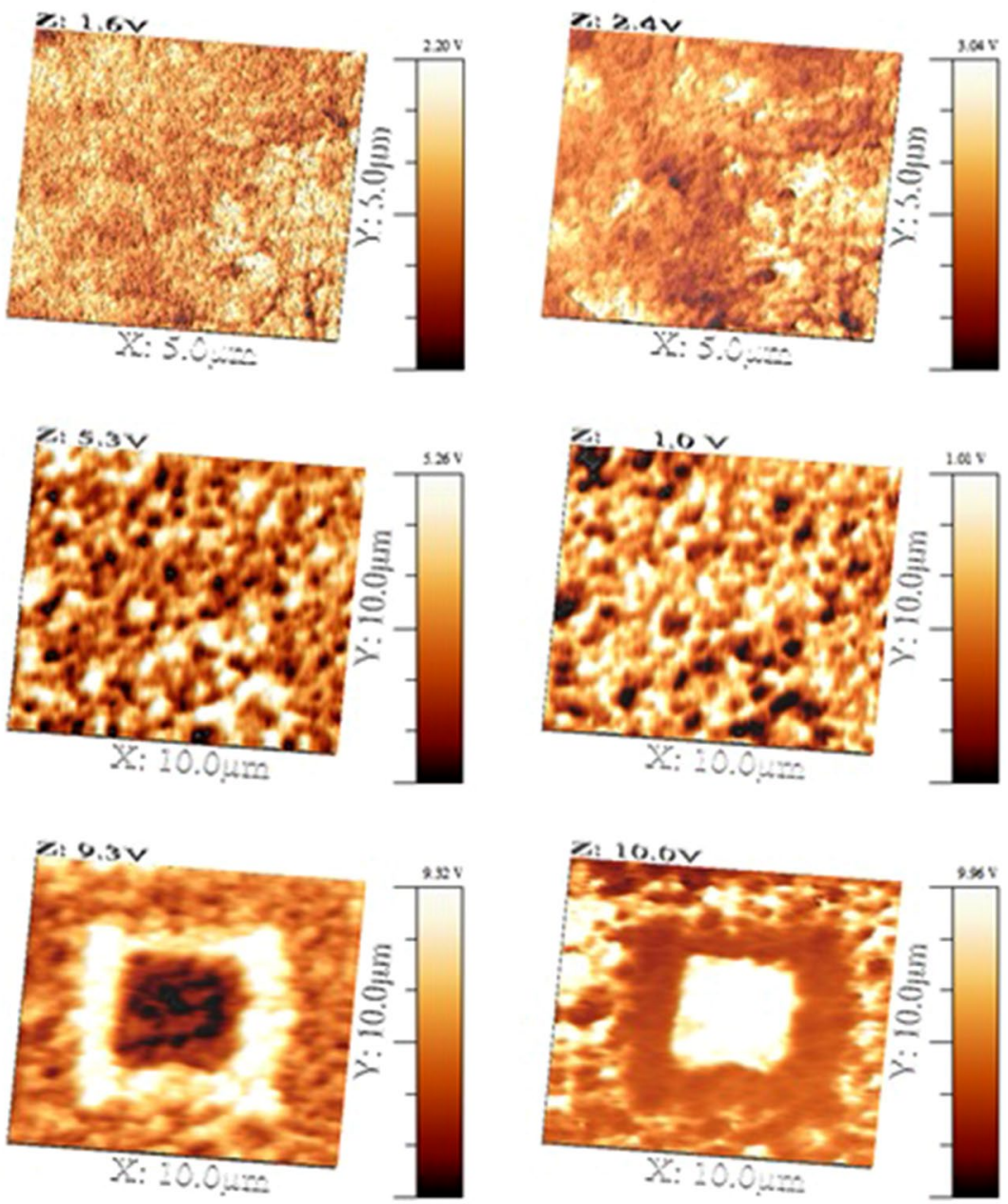

Fig. 6 Thin film surface topography (left), piezo-contrast amplitude (center), and piezo-contrast phase (right) of a film with annealing treatment $575^{\circ} \mathrm{C}$ for $22 \mathrm{~h}, \mathbf{b}$, c film with annealing treatment $550^{\circ} \mathrm{C}$ for $30 \mathrm{~min}$. Before and after lithographic bias poling at + and $-12.5 \mathrm{~V}_{\mathrm{dc}}$, respectively

time, though a slight decrease of $\mathrm{Bi} / \mathrm{Fe}$ ratio is observed for increasing annealing time. For the shorter time annealed films, a monoclinic structure with an additional tetragonal distortion is evidenced, compatible with a non-centrosymmetric structure. In this case, the expected emergence of ferroelectric domains was ascertained by PFM measurements. In summary, we propose a processing pathway for fabrication of BLFM films onto low cost metalized platinum substrates by performing deposition at temperatures below to $500^{\circ} \mathrm{C}$, in order to maintain the correct stoichiometry, followed by an annealing treatment at $550^{\circ} \mathrm{C}$ for a short time of about $30 \mathrm{~min}$. The crystallographic phase obtained allows for the existence of ferroelectric domains.

Acknowledgements This work was developed in the scope of the project FCT/CERN/FIS-NUC/0004/2015, Norte-070124FEDER-000070, I3N (PEst-C/CTM/LA0025/2013-14), CICECOAveiro Institute of Materials (UID/CTM/50011/2013), and PTDC/ FIS-NAN/0533/2012, Grant SFRH/BD/41331/2007; SFRH/ $\mathrm{BPD} / 80663 / 2011$ financed by national funds through the FCT/MEC, and when applicable co-financed by FEDER under the PT2020 Partnership Agreement.

\section{References}

1. G. Catalan, J.F. Scott, Adv. Mater. 21, 2463 (2009)

2. O. Dieguez, O.E. González-Vázquez, J.C. Wojdeł, J. Íñiguez, Phys. Rev. B 83, 094105 (2011)

3. H. Béa, M. Bibes, A. Barthélémy, K. Bouzehouane, E. Jacquet, A. Khodan, J.-P. Contour, S. Fusil, F. Wyczisk, A. Forget, D. Lebeugle, D. Colson, M. Viret, Appl. Phys. Lett. 87, 072508 (2005)

4. Z.-G. Mei, S. Shang, Y. Wang et al., Appl. Phys. Lett. 98, 131904 (2011)

5. D.H. Kuang, P. Tang, S.H. Yang, Y.L. Zhan, J. Sol-Gel Sci. Technol. 73410 (2015)

6. N. Somrani, A. Maaloul, H. Saidi, L. Stafford, M. Gaid, J. Mater. Sci. Mater. Electron. 26, 3316 (2015)

7. D. Sando, B. Xu, L. Bellaiche, V. Nagarajan, Appl. Phys. Rev. 3, 011106 (2016)

8. R.J. Zeches et al., Science 326, 977 (2009) 
9. D. Ricinschi, K.-Y. Yun, M. Okuyama, J. Phys. Condens. Matter 18, L97 (2006)

10. H. Béa et al., Phys. Rev. Lett. 102, 217603 (2009)

11. D.K. Pradhan, R.N.P. Choudhary, C. Rinaldi, R.S. Katiyar. J. Appl. Phys. 106, 024102 (2009)

12. D. Arnold, IEEE Trans. Ultrason. Ferroelectr. Freq. Control 1, 62 (2015)

13. Z. Xing et al., J. Am. Ceram. Soc. 97, 2323 (2014)

14. T.T. Carvalho et al., J. Alloy. Compd. 554, 97 (2013)

15. G. Kartopu, A. Lahmar, S. Habouti, C.L. Solterbeck, B. Elouadi, M. Es-Souni, App. Phys. Lett. 92, 151910 (2008)

16. A. Lahmar, K. Zhao, S. Habouti, M. Dietze, C.-H. Solterbeck, M. Es-Souni, Solid State Ion. 202, 1 (2011)

17. A. Lahmar, S. Habouti, C.-H. Solterbeck, M. Es-Souni, B. Elouadi, J. Appl. Phys. 105, 014111 (2009)

18. A. Lahmar, M. Es-Souni, Ceram. Int. 41, 5721 (2015)

19. J. Wu, J. Wang, Appl. Phys. 106054115 (2009)

20. D. Wang, N. Chan, R. Zheng, C. Kong, D. Lin, J. Dai, H.L. Chan, S. Li, J. Appl. Phys. 109, 114105 (2011)

21. D. Wang, R. Ding, S. Li, J. Am. Ceram. Soc. 96, 2531 (2013)

22. L. Feigl, P.-E. Janolin, T. Yamada, M. Iwanowska, C.S. Sandu, N. Setter, Appl. Phys. Lett. 106, 032902 (2015)
23. J. Kolte, A. Daryapurkar, P. Apte, P. Gopalan, Ferroelectrics 448, 42 (2013)

24. J. Kolte, A.S. Daryapurkar, M. Agarwal, D.D. Gulwade, P. Gopalan, Thin Solid Films 619, 308 (2016)

25. T.T. Carvalho, P.B. Tavares, Mater. Lett. 62, 3984 (2008)

26. S. Gómez-Salces, F. Aguado, F. Rodríguez, R. Valiente, J. González, R. Haumont, J. Kreisel, Phys. Rev. B 85, 144109 (2012)

27. F.J. Owens, J. Magn. Magn. Mater. 321, 2386 (2009)

28. Q. Wei, Z. Li, Z. Zhang, Q. Zhou, Mater. Trans. 50, 1351 (2009)

29. L. Martin-Carron, A. de Andres, M.J. Martinez-Lope, M.T. Casais, J.A. Alonso, Phys. Rev. B 66, 174303 (2002)

30. J.A. Moreira, A. Almeida, W.S. Ferreira, J.E. Araújo, A.M. Pereira, M.R. Chaves, J. Kreisel, S.M.F. Vilela, P.B. Tavares, Phys. Rev. B, 81, 054447 (2010)

31. P. Zaumseil, J. Appl. Cryst. 48, 528 (2015)

32. F.G. Figueiras, I. Bdikin, V.B.S. Amaral, A. Kholkin, Phys. Chem. Chem. Phys. 16(10) 4977-4981 (2014)

33. N. Balke, P. Maksymovych, S. Jesse, A. Herklotz, A. Tselev, C.-B. Eom, I.I. Kravchenko, P. Yu, S.V. Kalinin, ACS Nano 9, 6484 (2015) 